\title{
Babesia canis spp. in dogs in Baghdad Province, Iraq: First molecular identification and clinical and epidemiological study
}

\author{
Naseir Mohammed Badawi and Afaf Abdulrahman Yousif \\ Department of Internal and Preventive Veterinary Medicine, College of Veterinary Medicine, University of Baghdad, \\ Baghdad, Iraq. \\ Corresponding author: Naseir Mohammed Badawi, e-mail: naseir.badawi78@gmail.com \\ Co-author: AAY: afafabdulrahman57@gmail.com \\ Received: 26-11-2019, Accepted: 14-02-2020, Published online: 28-03-2020
}

doi: www.doi.org/10.14202/vetworld.2020.579-585 How to cite this article: Badawi NM, Yousif AA (2020) Babesia canis spp. in dogs in Baghdad Province, Iraq: First molecular identification and clinical and epidemiological study, Veterinary World, 13(3): 579-585.

\begin{abstract}
Aim: The aim of this study was to investigate babesiosis in dogs of different breeds and ages and of both sexes in Baghdad Province by molecular detection of Babesia canis using conventional polymerase chain reaction (PCR) and sequencing followed by phylogenetic analyses.

Materials and Methods: Blood samples were collected from 310 dogs of different ages and breeds, and of both sexes in different areas of Baghdad Province from December 2018 to September 2019; during clinical examinations, body temperature, pulse, respiratory rate, and signs of diseases were recorded. PCR was used to amplify a specific 450-bp fragment of the 18S rRNA gene of $B$. canis. PCR products were sequenced, and MEGA 6.0 software was used for analysis. Chi-square and odds ratio tests were used to investigate the prevalence and risk factors of babesiosis.

Results: Clinical signs of babesiosis included paleness or icterus of the mucus membranes, tick infestation, and febrile illness during the acute and subacute phase. The prevalence of infection with $B$. canis was $5.1 \%$, with the higher prevalence in male dogs and in dogs $<3$ years of age. Huskies were more likely to be infected than other dogs. Infection prevalence was highest in April and June and was higher in spring and summer than in winter. Using sequence data, 14 isolates of Babesia canis canis and one isolate of each Babesia canis rossi and Babesia canis vogeli were identified. Phylogenetic analyses of $B$. canis canis revealed that three shared clades and several isolated lineages were similar to other isolates (97-99\% similarity), whereas B. canis vogeli and B. canis rossi showed similarities of $98 \%$ and $99 \%$ with isolates from other geographical regions.
\end{abstract}

Conclusion: This study provides the first molecular record and phylogenic analysis of $B$. canis in dogs in Iraq, and it will be valuable for confirming clinical signs and studying epidemiological risk factors of babesiosis in dogs.

Keywords: 18S rRNA gene, Babesia canis, Baghdad, dog, Iraq.

\section{Introduction}

Canine piroplasms belong to two distinct species - the large Babesia canis, which measures 4-5 $\mu \mathrm{m}$ and is typically pear-shaped, and the small round Babesia gibsoni measuring 1-2.5 $\mu \mathrm{m}$. B. canis, according to antigenic properties, is sub-divided into three subspecies - Babesia canis canis which occurs in Europe, Babesia canis vogeli occurring in tropical and subtropical regions, and Babesia canis rossi which is found in South Africa [1]. Babesia can be transmitted by ticks, dog bites, and blood transfusions, and the pathogen can transgress the placental barrier [2]. Vertical transmission of $B$. canis (i.e., congenital infection) was shown by Mierzejewska et al. [3], who detected B. canis in pups of infected mother 7 weeks postpartum, and isolates from pups were $100 \%$ homologous with those of

Copyright: Badawi and Yousif. Open Access. This article is distributed under the terms of the Creative Commons Attribution 4.0 International License (http://creativecommons.org/licenses/ by/4.0/), which permits unrestricted use, distribution, and reproduction in any medium, provided you give appropriate credit to the original author(s) and the source, provide a link to the Creative Commons license, and indicate if changes were made. The Creative Commons Public Domain Dedication waiver (http:// creativecommons.org/publicdomain/zero/1.0/) applies to the data made available in this article, unless otherwise stated. their mothers. Vectors transmitting B. canis include Rhipicephalus sanguineus, Dermacentor reticulatus, and Haemaphysalis elliptica; small Babesia species in dogs, such as B. gibsoni, Babesia conradae, and Babesia microti-like species, can be transmitted by Haemaphysalis bispinosa, Haemaphysalis longicornis, wildlife reservoirs, and Ixodes hexagonus [4].

The first molecular study on B. canis in Iran was conducted by Bigdeli et al. [5], who found only one out of 280 dogs to be infected. In Turkey, Babesia was first detected in two dogs, according to clinical signs and blood smears, which was subsequently confirmed by polymerase chain reaction (PCR) [6]. The classic method of detecting $B$. canis using blood smears is considered the gold standard in acute and subacute cases [7]. Positive cases, as detected by blood smear, are necessarily also positive by PCR detection, whereas false-negative results obtained by microscopy may be found to be positive using PCR tests [8]. The specific primers PIRO-A1 and PIRO-B have been used previously to amplify a 450-bp region of the $18 \mathrm{~S}$ rRNA gene in B. canis and other Babesia species [9-15].

So far, no molecular studies on babesiosis in dogs have been conducted in Iraq, and all the previous 
studies on this disease were conducted using blood smear diagnosis. The first study reporting Piroplasma canis in a blood smear of one dog in Mesopotamia (present Iraq) was conducted in 1920 [16], and the first descriptions of B. gibsoni and B. canis in blood smears of dogs were produced in Nineveh (Mosul), Iraq [17]. Infection with $B$. gibsoni in Baghdad, Iraq, occurred in 52 out of $108 \mathrm{dogs}$, as diagnosed by Al-Taie and Fadhil [18] using blood smears.

In the present study, we investigated clinical and epidemiological parameters of babesiosis in dogs and, for the first time, performed molecular detection, sequencing, and phylogenetic analyses of $B$. canis in Iraq.

\section{Materials and Methods}

\section{Ethical approval}

All procedures used in the present study were approved by the Committee of College of Veterinary Medicine, University of Baghdad, approval number 7/2018.

\section{Animals and clinical examination}

Three hundred and ten dogs were examined at Baghdad Veterinary Hospital from December 2018 to September 2019. The dogs included 193 males and 117 females; 171 dogs were younger than 3 years and 139 were older than 3 years. We examined 191 German Shepherds, 65 Malinois, 14 huskies, 12 mongrels, ten terriers, four Rottweiler, three Labrador retriever, three Pekingese, two Lolo foxes, two Boo dogs, two Cocker spaniels, one sheepdog, and one Hawshar dog. All dogs were clinically examined, and body temperature, pulse, respiratory rate, and clinical signs of babesiosis were recorded.

\section{Sample collection}

Blood samples were collected from the cephalic vein and were placed in 2-mL EDTA tubes for microscopic examination; after this, samples were frozen until DNA isolation and PCR.

\section{Molecular genetic assay}

\section{DNA isolation}

A genomic DNA extraction kit was used to isolate DNA from blood (ReliaPrep ${ }^{\mathrm{TM}}$ Blood gDNA Miniprep System; Promega, USA). Quality and contraption of isolated DNA were assessed using a NanoDrop system (Thermo Scientific, Waltham, USA) and by agarose gel (1\%) electrophoresis using RedSafe Nucleic Acid Staining Solution (iNtRON, Seongnam, Korea). DNA purity ratios of $1.6-1.9$ at $260 / 280 \mathrm{~nm}$ were observed [19].

\section{PCR protocol}

We used primers targeting a 450-bp fragment of the 18S rRNA gene of B. canis, PIRO-A1 (5'-AGG GAG CCT GAG AGA CGG CTA CC-3') and PIRO-B (5'-TTA AAT ACG AAT GCC CCC AAC-3') [20,21]. The total PCR reaction volume of $25 \mu \mathrm{L}$ included $12.5 \mu \mathrm{L} 2 \times$ master mix containing 50 units $/ \mathrm{mL} \mathrm{Taq}$
DNA polymerase supplied in reaction buffer $(\mathrm{pH} 8.5)$, $3 \mathrm{mM} \mathrm{MgCl}, 400 \mu \mathrm{M}$ of each dNTP, $0.5 \mu \mathrm{L}$ of each primer (final concentration $10 \mathrm{pmol}$ ), $2 \mu \mathrm{L}$ template DNA, and $9.5 \mu \mathrm{L}$ nuclease-free water. All reagents were obtained from Promega. We used a thermal cycling protocol as described previously [10], comprising initial denaturation at $94^{\circ} \mathrm{C}$ for $10 \mathrm{~min}$, followed by 40 cycles of denaturation at $94^{\circ} \mathrm{C}$ for $30 \mathrm{~s}$, annealing at $60^{\circ} \mathrm{C}$ for $30 \mathrm{~s}$, extension at $72^{\circ} \mathrm{C}$ for 30 $\mathrm{s}$, and a final extension step at $72^{\circ} \mathrm{C}$ for $5 \mathrm{~min}$. PCR products were visualized using agarose gel $(1.5 \%)$ electrophoresis (Bio Basic, Canada), and gels were photographed under UV radiation using a digital camera (Bio-Rad Laboratories, USA).

\section{Sequencing and phylogenetic analyses}

PCR products were commercially sequenced (Macrogen, Korea) using the forward primer, and the sequences were aligned and compared with reference sequences of the $18 \mathrm{~S}$ rRNA gene of $B$. canis that was available in the NCBI database using BLAST (http:// www.ncbi.nlm.nih.gov/BLAST/). Phylogenetic trees were produced, and sequences were analyzed by multiple sequence alignment analyses using Molecular Evolutionary Genetics Analysis software (MEGA 6.0).

\section{Statistical analysis}

SPSS version 20.0 (IBM Corp., NY, USA) was used for statistical analysis. Chi-square tests were used for comparisons of prevalence levels (at $p \leq 0.05$ ), and multiple logistic regression analyses (odds ratio) were used to estimate potential babesiosis risk factors.

\section{Results}

Clinical signs in dogs with B. canis infections varied from acute phase and chronic to the development of carrier statuses with slight or inconspicuous clinical manifestation. Clinical signs differed between 16 infected dogs (Table-1), and the main signs were malnutrition, anorexia, and tick infestation (in five dogs; $31 \%$ ), vomiting and diarrhea (in three dogs; $18 \%$ ), and pale mucus membranes (in eight dogs; $50 \%$ ); in two dogs, sever icterus of the mucus membranes was observed after death (Figure-1). Clinical parameters included body temperatures of 37.7$40.5^{\circ} \mathrm{C}$ (only five dogs had a fever), respiratory rates of 19-69, and pulse rates of 60-136. Infected dogs

Table-1: The clinical signs of Babesia canis spp. among 16 dogs.

\begin{tabular}{lc}
\hline Clinical signs & Dogs (\%) \\
\hline Malnutrition & $5(31)$ \\
Depression & $9(56)$ \\
Anorexia & $8(50)$ \\
Nervous manifestation & $2(12.5)$ \\
Ticks infestation & $5(31)$ \\
Vomiting and diarrhea & $3(18)$ \\
Pale mucus membrane & $8(50)$ \\
Icterus and dead & $2(12.5)$ \\
Heartbeat weak & $7(43.7)$ \\
Irregular heart rhythm & $6(37.5)$ \\
\hline
\end{tabular}


showed no signs of urinary system such as oliguria, anuria, or hemoglobinuria. Ticks infestation was assessed as present or absent; however, ticks were not taxonomically identified.

Microscopic diagnosis revealed paired or single pear-shaped intra-erythrocyte large piroplasm $B$. canis (Figure-2), and out of 310 blood smears, $B$. canis spp. was observed 5 times, B. canis canis 4 times, and Babesia canis vogeli once. In contrast, PCR amplification and sequencing produced 16 cases of B. canis spp. (Figure-3), 14 cases of B. canis canis ( $4.51 \%)$, one case of $B$. canis vogeli $(0.32 \%)$, and one case of $B$. canis rossi $(0.32 \%)$. The total prevalence of $B$. canis spp. infections in dogs was $5.16 \%$ as determined by PCR, which was substantially higher than infection prevalence determined by microscopy $1.61 \%$ (Table-2).

The sequences of $18 \mathrm{~S}$ rRNA gene were made available at NCBI GenBank under the following accession numbers: B. canis canis: MN339533.1, MN339534.1, MN339535.1, MN339536.1, MN33 9537.1, MN339538.1, MN339539.1, MN339540.1, MN339541.1, MN339542.1, MN339543.1, MN 339544.1, MN339545.1, and MN339546.1; B. canis rossi: MN339547.1; and B. canis vogeli: MN 339549.1. Variation in taxonomic identification

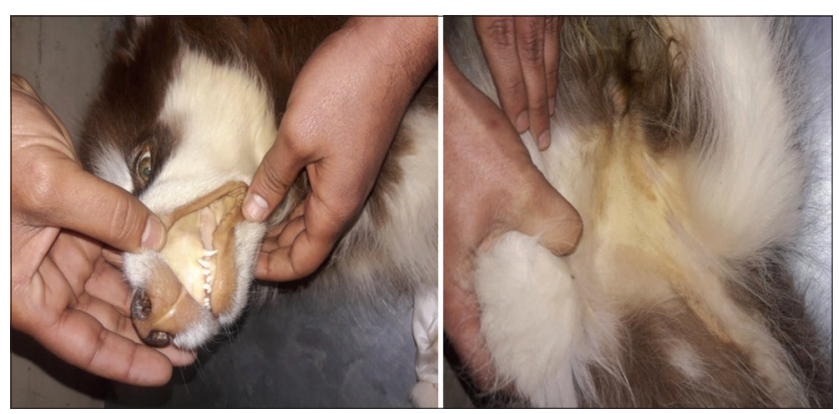

Figure-1: The dogs infected with Babesia canis suffered from severe blood hemolysis and icterus.

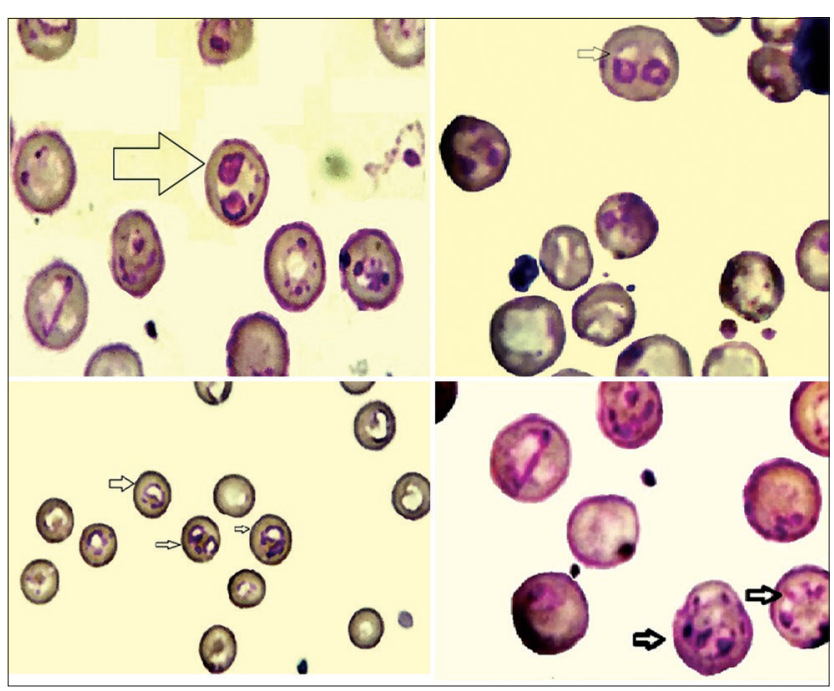

Figure-2: Babesia canis inside canine erythrocytes (intracellular) stained by Giemsa stain at (Light microscope $[100 \times])$. depended on query coverage, and out of 16 positive cases (5.16\%), 14 were infected by B. canis canis, and B. canis rossi and B. canis vogeli had infected one dog each.

A phylogenetic tree (Figure-4) of B. canis showed that the 14 B. canis canis isolates observed in the present study clustered in three clades: Clade 1 (MN339543.1 and MN339544.1) with 99\% similarity between isolates, clade 2 (MN339534.1 and MN339536.1) with 100\% similarity, clade 3 (MN339535.1, MN339539.1, MN339541.1, and MN339546.1) with 100\% similarity, and several isolated lineages(MN339533.1, MN339537.1, MN339538.1, MN339540.1, MN339542.1, and MN339545.1) with 97\% - 98\% similarity to other isolates. Phylogenetic analyses of $B$. canis isolates from different geographical regions (Slovenia, Croatia, Italy, Hungary, France, Russia, Romania, Turkey, Estonia, and Iran) showed 100\% similarity with clade 1 of the present study, and 99\% showed similarity with clade 2 , and clade 3 showed $97 \%$ similarity with isolates from different countries, while the isolated lineages of $B$. canis canis isolates of the present study showed $97 \%-98 \%$ similarity to other isolates. B. canis rossi was $99 \%$ similar to an isolate from Turkey (MK918605.1) and 100\% similar to an isolates from Montserrat, Spain (KP221649.1), and the USA (HM585429.1). B. canis vogeli identified in

Table-2: Comparison between microscope and PCR for diagnosis Babesia canis spp.

\begin{tabular}{lccc}
\hline Statues & Total dogs & Infected dogs & Percentage \\
\hline PCR & 310 & $16^{*}$ & 5.16 \\
Microscope & 310 & 5 & 1.61 \\
\hline
\end{tabular}

*Refer to increase significant at $\mathrm{p} \leq 0.05$ (Chi-square:5.7; $\mathrm{df}: 1 ; \mathrm{p}=0.01)$. $\mathrm{PCR}=$ Polymerase chain reaction

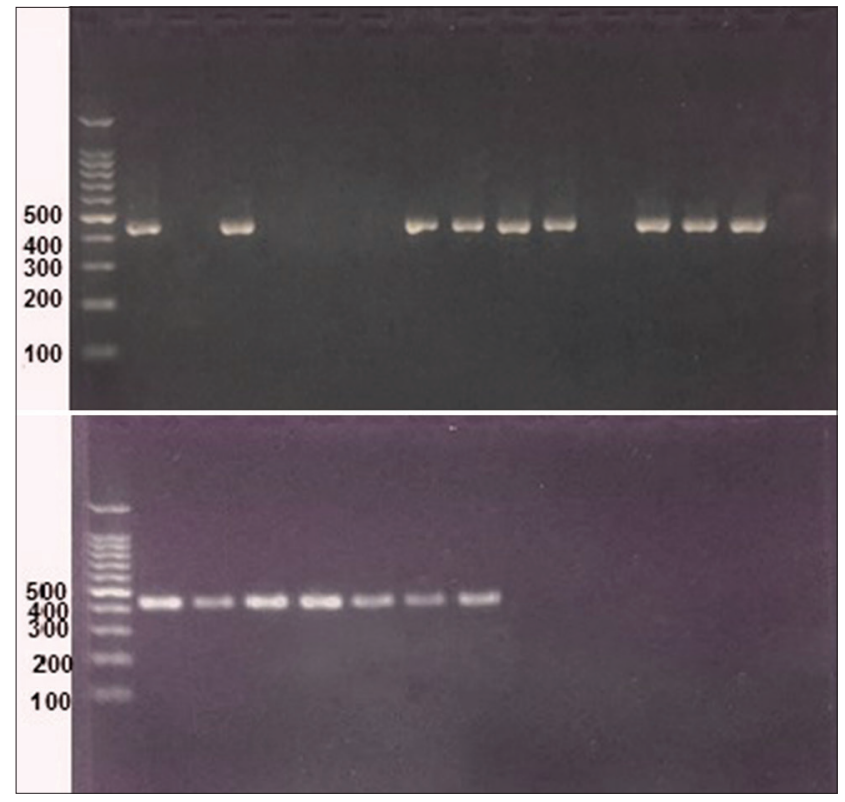

Figure-3: Babesia canis polymerase chain reaction amplicons of $18 \mathrm{~S}$ rRNA gene, 16 positive cases at 450 bp piro $A 1$ and piro $B$ primers (red safe stain), the first lane 100 bp DNA ladder. 


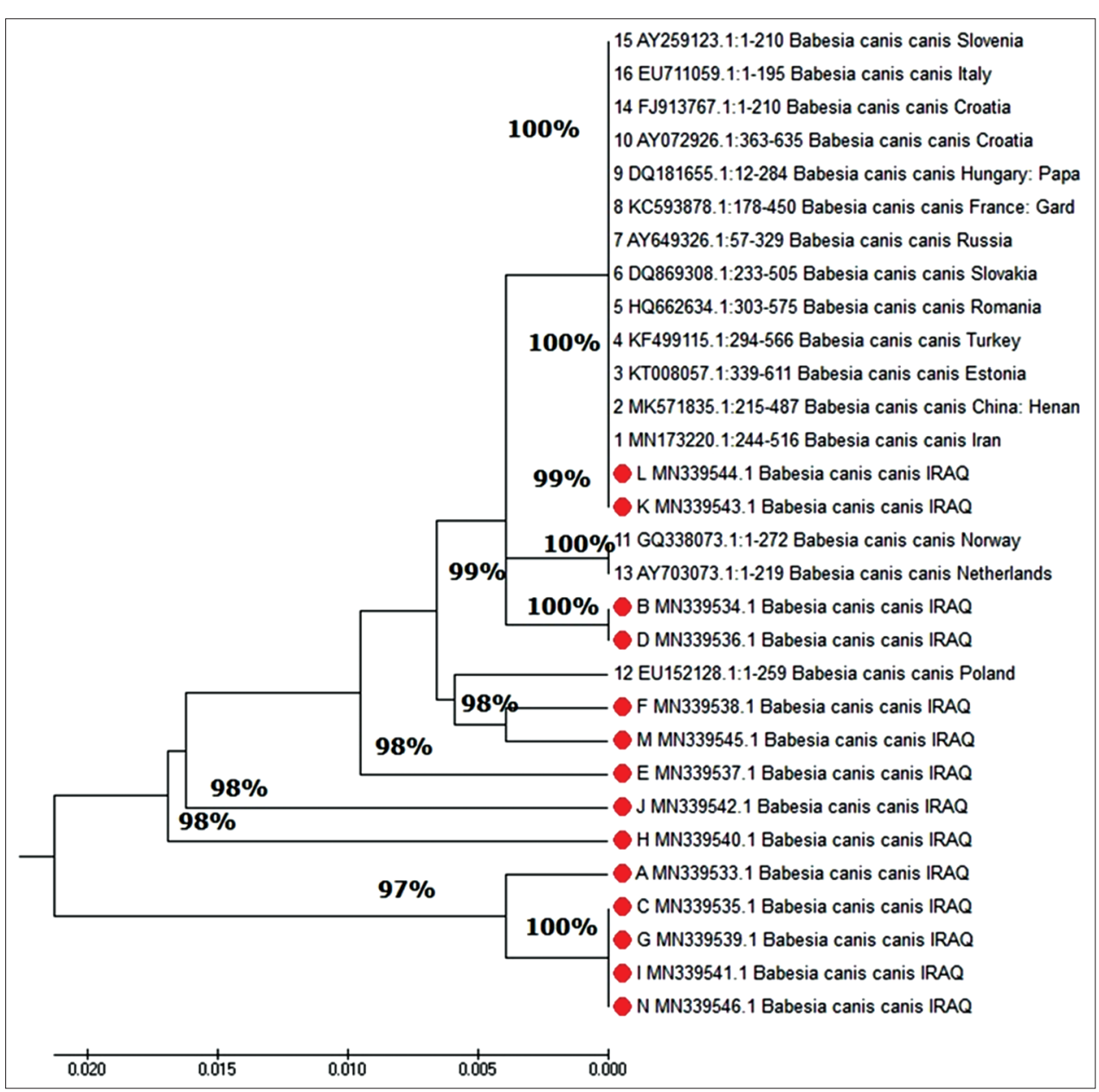

Figure-4: Phylogenetic tree of 18S rRNA gene of Babesia canis canis.

the current study was closest to the specimens from Japan (AB083374.1) and Sudan (DQ111756.1; 98\% similarity, each). The frequency of substitutions in $B$. canis nucleotide sequences in the present study revealed that a total of 44 transition substitutions and 27 transversion substitutions were observed in the 16 isolates, and the predominant substitutions were $A>G$ $(25 \%)$ and $\mathrm{T}>\mathrm{C}(26 \%)$.

Infection predisposition was examined by sex, and age (Table-3), and we found a higher but statistically non-significant risk of $B$. canis infection in males (odds ratio 1.81) compared to females. The probability of infection was higher in young dogs of up to 3 years of age than in older individuals (odds ratio 1.78), which was, however, not significant. B. canis infections were significantly more frequent in husky dogs (odds ratio 6.82) than in German Shepherds (Table-4). B. canis most commonly occurs in March, April, May, June, and July (Table-5), and the highest incidence was observed in April(13.7\%) and June $(10.2 \%)$. For statistical analyses, study months were assigned to three seasons, i.e., winter, spring, and summer, and the risk of $B$. canis infection in winter was zero; infection risk was higher in spring (odds ratio 1.73) than in summer; however, this difference was not significant.

\section{Discussion}

We described important clinical signs of babesiosis, such as malnutrition, anorexia, depression, and paleness of mucus membranes; icterus typically only occurs in the final stage of the disease and is associated with imminent death (as observed in two out of 16 infected dogs). Icterus was a non-significant sign, and we observed icterus in $12.5 \%$ of infected animals; however, $50 \%$ of all infected dogs showed pale mucus membranes. A previous study reported icterus in only $7.5 \%$ of infected dogs [15], whereas Davitkov et al. [14] observed icterus in $28 \%$ of dogs with babesiosis. In the present study, pale mucus membranes were substantially more common than icteric mucus membranes during $B$. canis infection which is likely due to severe anemia, whereas icterus only occurs after severe hemolysis in the final stage of this disease. Thus, $B$. canis can lead to fatal hemolytic anemia, which is typically associated with icteric mucus membranes.

In the present study, malnutrition was associated with chronic cases and long periods of anorexia; these signs typically occurred together with anemia, which is in line with the previous observations $[15,22]$. Some infected dogs had a fever with body temperatures up to $40.5^{\circ} \mathrm{C}$; however, this only occurred in the acute 
Table-3: Predisposition of sex and age in 16 dogs infected by Babesia canis spp.

\begin{tabular}{lc}
\hline Variables & Infected/Total dogs \\
\hline Sex & $12 / 193 *$ \\
Male & $4 / 117$ \\
Female & \\
Age (years) & $11 / 171^{* *}$ \\
$<3$ & $5 / 139$ \\
$>3$ & \\
\hline
\end{tabular}

*Confidence interval (CI 95\%) $=0.57-5.77$, Odds

ratio $=1.81 ; * *$ Confidence interval (CI) $95 \%=0.60-5.26$, Odds ratio $=1.78$

Table-4: Effect of breeds in 16 dogs infected by Babesia canis spp.

\begin{tabular}{lcc}
\hline Breed & Infected/Total & Significant \\
\hline German shepherd & $7 / 191$ & $\mathrm{~B}$ \\
Malinois & $4 / 65$ & \\
Husky* & $3 / 12$ & $\mathrm{~A}$ \\
Crossbreed & $2 / 14$ & \\
Other breed & $0 / 28$ & \\
\hline
\end{tabular}

*Confidence interval $($ CI 95\%) $=1.56-29.75$, Odds ratio $=6.82$.

Table-5: Number of infected dogs through months out of 16 dogs infected by Babesia canis spp.

\begin{tabular}{lcc}
\hline Months & $\begin{array}{c}\text { Infected/ } \\
\text { Total dogs }\end{array}$ & $\begin{array}{c}\text { Infected/Total } \\
\text { dogs }\end{array}$ \\
\hline December-2018 & $0 / 25$ & Winter \\
January-2019 & $0 / 25$ & $0 / 75$ \\
February-2019 & $0 / 25$ & \\
March-2019 & $2 / 25$ & Spring* \\
April-2019 & $4 / 29$ & $12 / 149$ \\
May-2019 & $1 / 46$ & \\
June-2019 & $5 / 49$ & Summer \\
July-2019 & $4 / 36$ & $4 / 86$ \\
August-2019 & $0 / 25$ & \\
September-2019 & $0 / 25$ & \\
*Confidence interval (CI 95\%) $=0.54-5.53$, Odds \\
ratio=1.73.
\end{tabular}

and subacute stages. Babesiosis is typically associated with febrile illness due to the production of endogenous pyrogens following hemolysis, immune responses to against parasite infection, and activation of inflammatory mediators during the acute and subacute phase [23]. In the current study, clinical signs associated with the acute and subacute phase included pale mucus membranes or icterus, tick infestation, febrile illness, and hemolysis, whereas malnutrition, anemia, and anorexia were considered symptoms of a chronic course of the disease.

According to sequencing data, B. canis canis was the most common species of Babesia in Baghdad, Iraq, with an infection prevalence of $4.51 \%$, while the prevalence of $B$. canis vogeli was $0.32 \%$ and that of $B$. canis rossi was $0.32 \%$. Total infection prevalence was $5.1 \%$, as detected by PCR; in contrast, B. canis infections were detected in only five dogs using blood smears $(1.61 \%)$, indicating a substantial number of false-negative results with this method. This is in line with the results of Da Silva et al. [24] who found low prevalence using microscopy diagnosis than with molecular methods. This considerable discrepancy in detection success is most likely due to the high sensitivity of PCR-based diagnosis and low parasitemia, particularly during the chronic phase or during carrier state.

Infection rates have been estimated based on molecular genetic methods by numerous researchers: B. canis infection prevalence was $3.3 \%$ in Sao Luis, Brazil [25], 3.75\% in Iran [1], and 3\% in India (B. canis vogeli) [26], all of which are below the prevalence observed in the current study; in Recife, Brazil, this value was $4.8 \%$ [14], which approximates that observed in the present study; however, other studies recorded the prevalence of $10.7 \%$ [27], $22.5 \%$ [15], 54\% [8], suggesting differences between countries, effects of study duration, and differences in control measures. Moreover, the geographical distribution of ticks and climate conditions facilitating transmission of $B$. canis also likely affect local prevalence. Local and seasonal distribution and abundance of ticks are, therefore, important epidemiological indications [26,27].

Transmission pathways are also important to consider, as direct transmission through dog bites is very likely in some studies [14]. In the current study, ticks were observed on $31 \%$ of infected dogs, which were within the range of previously reported tick infestation during canine babesiosis (55-14.8\%) [14,28]. However, no significant correlation of tick infestation and hemoparasites has been found [28]. While no taxonomic data on ticks were collected in the present study, a previous study found $R$. sanguineus in $21.56 \%$ of dogs in Baghdad Province [29].

Phylogenetic analyses of $18 \mathrm{~S}$ rRNA sequences produced three clades, with clade 1 comprising two isolates obtained from German Shepherd dogs, which differed by one nucleotide transition (A to G). Clade 2 differed from clade 1 by 1-2 nucleotide substitutions, and infected dogs of this clade were present in the same region in Baghdad Province. Clade 3 showed $97 \%$ similarity with other clades or isolates and varied in five nucleotide positions. Homology analyses of one isolate to each $B$. canis rossi and B. canis vogeli revealed polymorphisms in two and four nucleotide positions, respectively, and B. rossi showed $99 \%$ similarity with isolates from other geographical regions. B. canis rossi occurred in a Malinois dog of 2 years of age in March, while $B$. canis vogeli was isolated from a German Shepherd of 6 years of age in July. B. vogeli showed $98 \%$ similarity with isolates from other geographical regions.

Our results suggest that sex may be a risk factor for $B$. canis infection, as infection prevalence was higher in males than in females, which is in line with the results of several previous studies [24,30,31]; however, female-biased $B$. canis infection prevalence has also been reported $[1,23]$. In the current study, 
dogs younger than 3 years showed higher infection prevalence than older individuals, which have been reported previously $[1,15,24]$. This may be due to their immature immune system [15]. In Iraq, the typical vaccination protocol comprises polyvalent vaccines against seven diseases, and vaccination against canine distemper and parvovirus are typically administered to young dogs. According to the previous study, it found that the stress factor due to vaccination has an effect on the immune system of young dogs, which is crucial for fighting off B. canis infections [3].

Our results indicated that huskies and mongrels were more susceptible to $B$. canis infection than Malinois and German Shepherd dogs; however, the previous studies found comparably high infection rates in German Shepherds [15,23,32]; however, in the present study, B. canis infection was significantly more common in huskies than in other breeds and was more common in mongrels than in other breeds, which was not significant. We, therefore, suggest low tolerance of huskies to the environment in Iraq, which makes them more susceptible to diseases; moreover, mongrels are typically stray dogs that are exposed to hard climate conditions, which may also contribute to reduced immunity.

The highest incidence of canine babesiosis was observed in April and June, which is similar to the results of Tayyub et al. [33]. Furthermore, the highest number of positive cases occurred in spring and summer, likely because of increased exposure to ticks during these seasons [1] and warm and humid climate conditions favoring disease transmission by vectors [33].

\section{Conclusion}

The results of the present study indicate that $B$. canis canis is the predominant species causing Babesia infections in dogs in the region of Baghdad, Iraq. PCR assay and sequence analyses are more sensitive diagnostic methods than microscopy examination. Furthermore, potential risk factors such as sex, age, and period of infection were investigated in this study, and the results suggest that the frequent monitoring of canine babesiosis in Iraq would be required to reduce the prevalence of Babesia.

\section{Authors' Contributions}

NMB: Study idea, planning, and design. Conduct of the clinical, hematological, molecular methods, statistical analysis, and manuscript writing. AAY: Supervisor and guidance in the study, results interpretation, and revision of the manuscript. All authors read and approved the final manuscript.

\section{Acknowledgments}

The authors are thankful to the Department of Internal and Preventive Veterinary Medicine, College of Veterinary Medicine, University of Baghdad, and Baghdad Veterinary Hospital/Iraq for providing facilities. The authors did not receive any funds for this study.

\section{Competing Interests}

The authors declare that they have no competing interests.

\section{Publisher's Note}

Veterinary World remains neutral with regard to jurisdictional claims in published institutional affiliation.

\section{References}

1. Jalali, M.H.R., Mosallanejad, B., Avizeh, R., Alborzi, A.R., Hamidinejat, H. and Taghipour, R. (2013) Babesia infection in urban and rural dogs in Ahvaz district, Southwest of Iran. Arch. Razi Inst., 68(1): 37-42.

2. Goo, Y. and Xuan, X. (2014) New molecules in Babesia gibsoni and their application for diagnosis, vaccine development, and drug discovery. Korean J. Parasitol., 52(4): 345-353.

3. Mierzejewska, E.J., Welc-Faleciak, R., Bednarska, M., Rodo, A. and Bajer, A. (2014) The first evidence for vertical transmission of Babesia canis in a litter of Central Asian Shepherd dogs. Ann. Agric. Environ. Med., 21(3): 500-503.

4. Birkenheuer, A.J. (2012) In: Greene, C.E., editor. Infectious Diseases of the Dog and Cat, Chapter 76: Babesiosis. $4^{\text {th }}$ ed. Elsevier, St. Louis, p771-784.

5. Bigdeli, M., Rafie, S.M., Namavari, M.M. and Jamshidi, S. (2012) Report of Theileria annulata and Babesia canis infections in dogs. Comp. Clin. Path., 21(3): 375-377.

6. Aysul, N., Ural, K., Ulutaş, B., Eren, H. and Karagenç, T. (2013) First detection and molecular identification of Babesia gibsoni in two dogs from the Aydın Province of Turkey. Turk. J. Vet. Anim. Sci., 37(2): 226-229.

7. Lira-Amaya, J.J., Rojas-martinez, C., Alvarez, A., Pelaezflores, A., Martinez-ibañez, F., Rosa, D.P. and Figueroamillan, J.V. (2017) First molecular detection of Babesia canis vogeli in Dogs and Rhipicephalus sanguineus from Mexico. Arch. Palliat. Care, 2(2): 2-5.

8. Laha, R., Bhattacharjee, K., Sarmah, P.C., Das, M., Goswami, A., Sarma, D. and Sen, A. (2014) Babesia infection in naturally exposed pet dogs from a north-eastern state (Assam) of India: Detection by microscopy and polymerase chain reaction. J. Parasit. Dis., 38(4): 389-393.

9. Jefferies, R., Ryan, U.M., Muhlnickel, C.J. and Irwin, P.J. (2003) Two species of canine Babesia in Australia: Detection and characterization by PCR. J. Parasitol., 89(2): 409-413.

10. Földvári, G., Hell, E. and Farkas, R. (2005) Babesia canis canis in dogs from Hungary: Detection by PCR and sequencing. Vet. Parasitol., 127(3-4): 221-226.

11. de Sa, A.G., Figueiredo, A.M., O Dwyer, L.H., Macieira, D.D., Da Silva, F., Ferreira, R.F. and Almosny, N.R.P. (2006) Detection and molecular characterization of Babesia canis vogeli from naturally infected Brazilian dogs. Int. J. Appl. Res. Vet. Med., 4(2): 163-168.

12. O'Dwyer, L.H., Lopes, V.V., Rubini, A.S., Paduan, K.D.S. and Ribolla, P.E. (2009) Babesia spp. infection in dogs from rural areas of São Paulo State, Brazil. Rev. Bras. Parasitol. Vet., 18(2): 23-26.

13. Buddhachat, K., Meesong, O., Nganvongpanit, K., Osathanunkul, M. and Chomdej, S. (2012) Molecular characterization and detection of Babesia canis vogeli in asymptomatic roaming dogs in Chiang Mai, Thailand. Thai J. Vet. Med., 42(2): 173-178.

14. Davitkov, D., Vucicevic, M., Stevanovic, J., Krstic, V., Tomanovic, S., Glavinic, U. and Stanimirovic, Z. (2015) Clinical babesiosis and molecular identification of Babesia 
canis and Babesia gibsoni infections in dogs from Serbia. Acta Vet. Hung., 63(2): 199-208.

15. Mahalingaiah, M.K.C., Asoor, M., Thimmaiah, R.P., Narayanaswamy, H.D., Mukartal, S.Y., Elattuvalappil, A.M., Chikkahonnaiah, N., Gupta, S. and Singh, S. (2017) Prevalence of canine babesiosis in different breeds of dogs in and around Bengaluru. Adv. Anim. Vet. Sci., 5(3): 140-144.

16. Patton, W.S. (1920) Some notes on the arthropods of medical and veterinary importance in Mesopotamia, and on their relation to disease. Part V. Indian J. Med. Res., 8(2): 253-256.

17. Arsalan, S.H. (2005) Clinical, haematological and biochemical studies of some blood protozoa in dogs in Nineveh. Iraqi J. Vet. Sci., 1(19): 63-77.

18. Al-Taie, D.A. and Fadhil, A.I. (2013) Incidence of Babesia gibsoni in stray dogs (Iraq). Online J. Vet. Res., 17(1): 32-35.

19. Voytas, D. (2000) Agarose gel electrophoresis. Curr. Protoc. Mol. Biol., 51(1): 2-5.

20. Muhlnickel, C.J., Jefferies, R., Morgan-Ryan, U.M. and Irwin, P.J. (2002) Babesia gibsoni infection in three dogs in Victoria. Aust. Vet. J., 80(10): 606-610.

21. Olmeda, A.S., Armstrong, P.M., Rosenthal, B.M., Valladares, B., Del Castillo, A., de Armas, F. and Spielman, A. (1997) A subtropical case of human babesiosis. Acta Trop., 67(3): 229-234.

22. Zygner, W., Gojska-Zygner, O., Długosz, E. and Wędrychowicz, H. (2011) Liver enzyme activity in dogs infected with Babesia canis. Bull. Vet. Inst. Pulawy, 55(3): 423-427.

23. Salem, N.Y. and Farag, H.S. (2014) Clinical, hematologic, and molecular findings in naturally occurring Babesia canis vogeli in Egyptian dogs. Vet. Med. Int., 2014: Article ID 270345.

24. Da Silva, V.C.L., De Lima, E.R., Dias, M.B., Fukahori, F.L.P., Rego, M.S., Júnior, J.W.P., Kim, P.C., Leitão, R.S., Mota, R.A. and Carieli, E.P. (2016) Parasitological and molecular detection of Babesia canis vogeli in dogs of Recife, Pernambuco and evaluation of risk factors associated. Semina. Ciênc. Agrár., 37(1): 163-171.

25. Silva, A.B., Costa, A.P., de Sá, J.C., Costa, F.B., Dos Santos, A.C.G. and de Maria, S.N.C. (2012) Detecção molecular de Babesia canis vogeli em cães e em Rhipicephalus sanguineus na mesorregião do oeste maranhense, nordeste brasileiro. Ciênc. Anim. Bras., 13(3): 388-395.

26. Sarma, K., Biala, Y.N., Kumar, M. and Baneth, G. (2019) Molecular investigation of vector-borne parasitic infections in dogs in Northeast India. Parasit. Vectors, 12(1): 122.

27. Jain, J., Lakshmanan, B., Nagaraj, H.V., Praveena, J.E., Syamala, K. and Aravindakshan, T. (2018) Detection of Babesia canis vogeli, Babesia gibsoni and Ehrlichia canis by multiplex PCR in naturally infected dogs in South India. Vet. Arhiv., 88(2): 215-224.

28. Ribeiro, C.M., Matos, A.C., Azzolini, T., Bones, E.R., Wasnieski, E.A., Richini-Pereira, V.B. and Vidotto, O. (2017) Molecular epidemiology of Anaplasma platys, Ehrlichia canis and Babesia vogeli in stray dogs in Paraná, Brazil. Pesqui. Vet. Bras., 37(2): 129-136.

29. Fadhil, A.I. (2014) Prevalence study of hard tick Rhipicephalus sanguineus in stray dogs form many areas from Baghdad Province. Iraqi J. Vet. Med., 38(2): 9-11.

30. Araujo, A.C., Silveira, J.A.G., Azevedo, S.S., NieriBastos, F.A., Ribeiro, M.F.B., Labruna, M.B. and Horta, M.C. (2015) Babesia canis vogeli infection in dogs and ticks in the semiarid region of Pernambuco, Brazil. Pesqui. Vet. Bras., 35(5): 456-461.

31. de Marco, M.D.M., Hernández-Triana, L.M., Phipps, L.P., Hansford, K., Mitchell, E.S., Cull, B., Swainsbury, C.S., Fooks, A.R., Medlock, J.M. and Johnson, N. (2017) Emergence of Babesia canis in southern England. Parasit. Vectors, 10(1): 1-9.

32. Akhtardanesh, B., Saberi, M., Nurollahifard, S.R. and Aghazamani, M. (2016) Molecular detection of Babesia spp. in tick-infested dogs in Southeastern Iran. J. Dis. Glob. Health, 8(2): 72-77.

33. Tayyub, M., Ashraf, K., Lateef, M., Anjum, A.A., Ali, M.A., Ahmad, N. and Nazir, M.M. (2019) Genetic diversity of canine Babesia species prevalent in pet dogs of Punjab, Pakistan. Animals, 9(7): 439. 